\title{
Correction to: Rhythmic and speech rate effects in the perception of durational cues
}

\section{Jeremy Steffman ${ }^{1}$}

Published online: 29 July 2021

(C) The Psychonomic Society, Inc. 2021

\section{Correction to: Attention, Perception, \& Psychophysics https://doi.org/10.3758/s13414-021-02334-w}

The original version of footnote 9 contains an error; footnote 9 should read:

"This is also worth considering in light of the finding that repeating speech can sometimes be perceived as sung, i.e., the speech-to-song illusion (Deutsch, Henthorn, and Lapidis, 2011), which might impact listeners' perception of rhythmic timing patterns."

The original version of this footnote 9 read:

"This is also worth considering in light of the finding that repeating speech can sometimes be perceived as sung, i.e., the speech-to-song illusion (Deutsch, Henthorn, and Lapidis, 2011), which might impact possessive listeners' perception of rhythmic timing patterns."

Publisher's note Springer Nature remains neutral with regard to jurisdictional claims in published maps and institutional affiliations.

The online version of the original article can be found at https://doi.org/ 10.3758/s13414-021-02334-w

Jeremy Steffman

jeremy.steffman@northwestern.edu

1 Northwestern Department of Linguistics, 2016 Sheridan Road,

Evanston, IL 60208, USA 